\title{
Cerebrospinal Fluid Rhinorrhea in a Sino Nasal Low Grade Non Intestinal Adenocarcinoma: Which Association? A Case Report and Literature Review
}

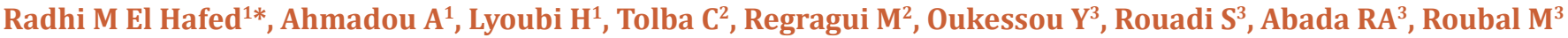 \\ and Mahtar $\mathbf{M}^{3}$
}

${ }^{1}$ ENT-HNS Department, Casablanca, Morocco

${ }^{2}$ Anatomopathology Department, Casablanca, Morocco

${ }^{3}$ ENT-HNS Department, Casablanca, Morocco

Submission: March 02, 2020; Published: April 03, 2020

*Corresponding author:Radhi M El Hafed, ENT-HNS Department, Casablanca, Morocco

\begin{abstract}
Sinonasal low- grade non-intestinal-type adenocarcinoma (LG non-ITAC) is an uncommon neoplasm, there is no sexual or racial predilection, nasal obstruction, epistaxis are common symptoms, but in presence of rhinorrhea we have to differentiate between serous nasal secretions and rhinorrhea of cerebrospinal fluid (CSF). The main risk in failing to recognize a CSF leak is meningitis. Well treated the prognosis is excellent. We describe a case of A 60 years old woman who presented a 2 years history of recurrent left- sided epistaxis associated with nasal obstruction and clear rhinorrhea, B2 transferrin test has confirmed the CSF rhinorrhea, imaging by CT SCAN and MRI has suspected a small bony defect in cribriform plate, and the histological analysis concluded to a LG non-lTAC, surgery was performed endoscopic ally with complete extirpation of the tumor and repair of the bone defect; in the short follow up there was no signs of rhinorrhea or epistaxis. The treating physician needs a high index of suspicion and often a great deal of persistence in diagnosing for CSF rhinorrhea even in case of LG non-lTAC. To the best of our knowledge, this is the first case of a LG non-ITAC with cerebrospinal fluid rhinorrhea.
\end{abstract}

keywords: Low Grade Adenocarcinoma; Cerebrospinal Fluid; Rhinorrhea; Non-intestinal Adenocarcinoma

\section{Introduction}

Sinonasal adenocarcinoma (SNAC) represents $10 \%$ to $20 \%$ of all Sinonasal malignancies [1], the 2017 WHO classification distinguishes two main categories: intestinal type adenocarcinoma (ITAC) and non-intestinal adenocarcinoma (non-lTACs). Sinonasal low- grade non-intestinal-type adenocarcinomas (LG non-lTACs) are very uncommon [2], well treated the prognosis is excellent. We describe a case of a LG non-ITACs associated with a cerebrospinal fluid (CSF) rhinorrhea.

\section{Case Report}

60 years old woman with no history of tobacco use, or exposure to wood dust or other known carcinogens, reported 2 years history of recurrent left- sided epistaxis associated with permanently left nasal obstruction. The patient also reported a clear rhinorrhea evolving for 1 year; his medical history and family history are otherwise unremarkable. Examination of the left nasal cavity found a lobulated hyper vascular mass bleeding on contact, in front of left medial turbinate; the right nasal cavity and the remainder of the physical examination were unremarkable. Computed tomographic scan revealed an expansive process occupying the left nasal cavity, maxillary sinus and few ethmoidal cells (Figure 1).

To better assess the extent and origin of the mass, a MRI with injection of gadolinium was performed, showing a tumor process of the left nasal cavity extending to the left choana, intensely enhanced after injection, measuring 54*34*16 mm, highlighting in T2 coronal sequences a small communication measuring 2 $\mathrm{mm}$ between under arachnoid space and left nasal cavity (Figure 2). The fluid was tested for beta-2-transferrin and found to be positive. The histopathological analysis showed that tumor proliferation is arranged in often back-to-back tubes and papillae, tumor cells are cylindrical with eosinophilic cytoplasm with basal nuclei (Figure 3).

An immunohistochemical study has been carried out, it shows that tumor cells express cytokeratin 7 (Figure 4), with no express of cytokeratin 20 and CDX2. Based on histologic and immunohistochemical features, we diagnosed a LG non-lTAC. Exclusive endoscopic resection was performed, and the tumor was completely excised. The ethmoidectomy is done and the small bony defect has been closed by an overlay free mucosal graft. 
After discussion with oncologists, we have decided that adjuvant radiotherapy is unnecessary. Patient is currently 2 months after surgery and there was no evidence of rhinorrhea or epistaxis.

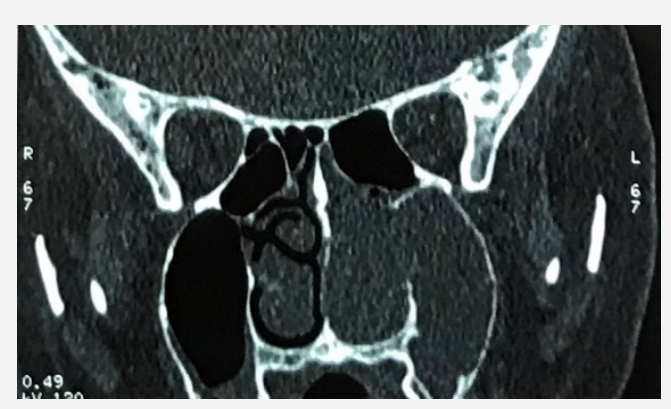

Figure 1: CT SCAN showing the large mass in left nasal cavity with extension to maxillary and ethmoidal sinus.

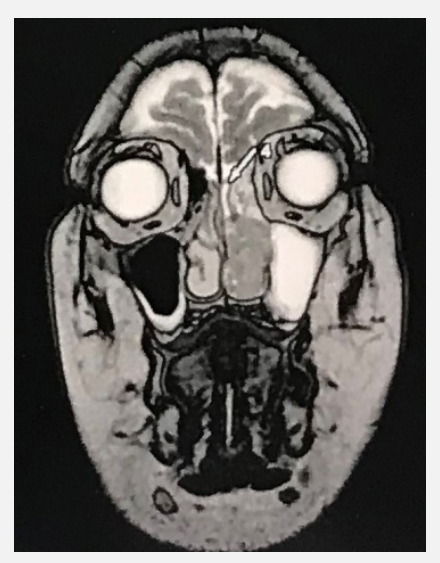

Figure 2: Coronal T2 image, shows a small communication between under arachnoid space and the nasal cavity (arrow).

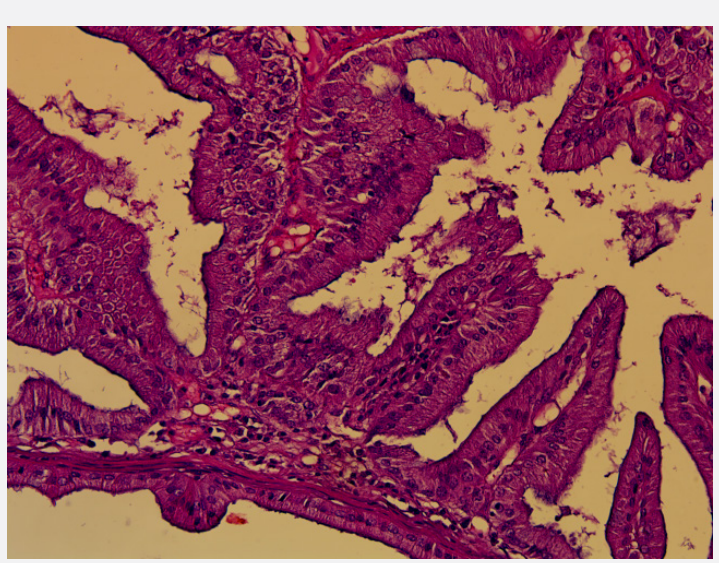

Figure 3: Hematoxylin and eosin x 200; shows a predominately papillary feature.

\section{Discussion}

Primary adenocarcinomas of the Sinonasal tract are a heterogeneous group [1], Sinonasal non-intestinal-type adenocarcinoma (non-lTAC) is an adenocarcinoma of the
Sinonasal tract that does not show the features of a salivary gland neoplasia and does not have an intestinal phenotype [2]. Lowgrade non-ITACs do not show sex or racial predilection and are more common after 50 years of age [3], in our knowledge there is no known etiology for LG non-lTACs.

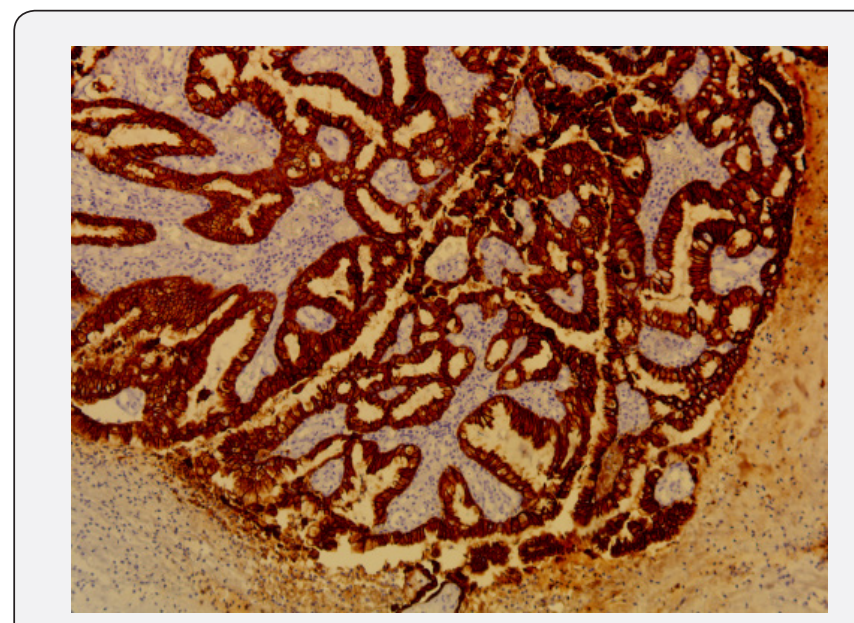

Figure 4: Tumor cells express cytokeratin 7.

No risk factors, predisposing conditions, or environmental exposures have been described for non-ITACs [3] Most patients presented with unilateral nasal obstruction, recurrent epistaxis; and the Most site occurred is the nasal cavity [1]. the distinction between serous nasal secretions and fluids that leak down into the nose from the brain through a pathologic opening can perplex the most intrepid physician; and The best contemporary chemical test at present to diagnosed a CSF rhinorrhea is the beta 2 transferrin, by electrophoresis or immunofixation [4].

Diagnostic imaging is recommended by the couple CT scan/ MRI to better define the mass and eventual local extension into adjacent structures, in our case we have noticed a minimally meningocele which probably means an invasion of skull of base. Surgical excision remains the treatment of choice [5]. Many approaches had been described, thus ranges from craniofacial resection to endoscopic techniques, Endoscopic approaches to the skull base and Sinonasal regions offer an excellent visualization and a complete extirpation of the tumor with lower morbidity [6], followed by postoperative radiotherapy in patients with close margins or incomplete resection [7], Interestingly in the study of Aryan Shay [8], they found that radiotherapy made no difference in median survival time among patients with low-grade SNAC who had positive margins after primary surgery. However, in our case the resection of tumor was complete and was no needed adjuvant radiotherapy.

The ethmoidectomy is done to gain wide and easy exposure to the defect in the roof of the cribriform plate [9]. There are a multiples variety of techniques described in the literature for closing the leak, By single or multiple-layer closures with or without bone or artificial material. The 2017 WHO classification of head and neck tumors [2] highlight that LG non-ITACs are predominately 
papillary and/or tubular features with complex growth, including back-to-back glands with little intervening stroma. These cells have eosinophilic cytoplasm and uniform, basally located nuclei. Mitotic figures are rare; the immunohistochemical analysis showed that non-ITACs reveal a respiratory-type profile (CK20-, CK7+, CDX2-, and MUC2-).

For treatment planning and prognosis, it is important to distinguish low-grade adenocarcinomas from high-grade adenocarcinomas. LG Non-ITACs tends to be more localized at presentation and carries a favorable prognosis; only $6 \%$ of patients die from their tumours, usually as a result of loss of local control [10]. Our case highlights the importance for complete investigation in present of rhinorrhea and always maintaining a high clinical index of suspicion for The CSF rhinorrhea even in case of LG non-ITAC.

\section{References}

1. Barnes L (1986) Intestinal-Type Adenocarcinoma of the Nasal Cavity and Paranasal Sinuses: Am J Surg Pathol 10(3): 192-202.

2. EI Naggar AK, C han J K C G, Randis J R, Takata T, Slootweg P J (Eds) (2017) WHO Classification of Head and Neck Tumours (4th edition) IARC: Lyon, France.

3. Heffner DK, Hyams VJ, Hauck KW, Lingeman C (1982) Low-grade adenocarcinoma of the nasal cavity and paranasal sinuses. Cancer 50(2): 312-322.

4. Bateman N, Jones NS (2000) Rhinorrhoea feigning cerebrospinal fluid leak: nine illustrative cases. J Laryngol Otol 114(6): 462-464.

5. Van Gerven L, Jorissen M, Nuyts S, Hermans R, Vander Poorten V (2011) Long-term follow-up of 44 patients with adenocarcinoma of the nasal cavity and sinuses primarily treated with endoscopic resection followed by radiotherapy. Head Neck 33(6): 898-904.

6. Hanna E, DeMonte F, Ibrahim S, Roberts D, Levine N, et al. (2009) Endoscopic Resection of Sinonasal Cancers with and Without Craniotomy: Oncologic Results. Arch Otolaryngol Neck Surg 135(12): 1219.

7. Lund VJ, Chisholm EJ, Takes RP, Suárez C, Mendenhall WM, et al. (2012) Evidence for treatment strategies in sinonasal adenocarcinoma. Head Neck 34(8): 1168-1178.

8. Shay A, Ganti A, Raman A, Kuhar HN, Auger SR, et al. (2020) Survival in low-grade and high-grade sinonasal adenocarcinoma: A national cancer database analysis. The Laryngoscope 130(1).

9. Kerr JT, Chu FWK, Bayles SW (2005) Cerebrospinal Fluid Rhinorrhea: Diagnosis and Management. Otolaryngol Clin North Am 38(4): 597611.

10. Janz TA, Graboyes EM, Nguyen SA, Ellis MA, Neskey DM, et al. (2019) A Comparison of the NCDB and SEER Database for Research Involving Head and Neck Cancer. Otolaryngol Neck Surg 160(2): 284-294.

\section{Your next submission with Juniper Publishers will reach you the below assets}

- Quality Editorial service

- Swift Peer Review

- Reprints availability

- E-prints Service

- Manuscript Podcast for convenient understanding

- Global attainment for your research

- Manuscript accessibility in different formats

( Pdf, E-pub, Full Text, Audio)

- Unceasing customer service

Track the below URL for one-step submission https://juniperpublishers.com/online-submission.php 